\title{
STUDY OF THE STOOLS IN CHILDREN'S INSTITUTIONS SHOWING THE INCIDENCE OF INTESTINAL PARASITIC INFECTIONS
}

\author{
L. R. DE BUYS, B.S., M.D. \\ Professor of Pediatrics, School of Medicine, Tulane University \\ NEW ORLEANS, LA. \\ AND
}

H. L. DWYER, M.D.

KANSAS CITY, MO.

This study consisted in the examination of the stools of 595 individuals in seven institutions. The ages of the inmates varied from three months to eighteen years and included institutions in which there were both males and females.

The method of examination was as follows: The stools were secured at the various institutions and placed in pill boxes, and each box was labeled with the name of the individual from whom it was obtained. The stool was thoroughly macerated in distilled water and filtered through several thicknesses of gauze. The filtrate was then placed in a centrifuge with a velocity of 1,500 revolutions per minute for from ten to twelve seconds, after which the supernatant fluid was discarded, the residue again thoroughly mixed with distilled water and again centrifuged for a like period. If the fluid after the second centrifuging continued cloudy the residue. was again washed and centrifuged a third time. Then the water was poured off and the residue spread on a slide. The examination was made with a minimum of light. This precaution was taken so as not to miss Hymenolepis nana, which is very translucent: The preparation was made thin enough for newspaper print to be discernible through it.

The specimen was then placed under the microscope and examined with the lower power to find the ova and then with the higher power for closer study and differentiation.

The time required for the examination of a specimen varies considerably depending on the severity of the infection and the character of the stool. Stools from purges are more difficult to examine. If watery, the preparation is cloudy and if there is much mucus it probably interferes with the ova being thrown to the bottom of the test tube. In this series no stool was considered negative until about one-half hour's search failed to reveal anything. Cercomonas and trichomonas were found in about fifteen instances in the stools examined. 
Observations were made on the test tubes in which heavily infected specimens were contained to determine the possibility of ova being carried over in subsequent examinations and increasing the positive findings. It was shown, however, that after being washed and boiled the findings were negative on repeated examinations. This dispelled the possibility of the ova adhering to the sides of the tubes being hard to remove. No tubes were used twice on the same day.

In making the examinations of blood the stool findings were not kept in mind, the counting being done independently.

The stools were secured from seven institutions, which included four orphan asylums, one infant asylum and two waifs' homes. The number of inmates in the institutions were, respectively, 95, 125, 75, $67,110,51$ and 72 ; a total of 595 .

Of the 595 individuals whose stools were examined, 317 , or 53.27 per cent., were infected. Of the 595,211 , or 35.47 per cent., had single infections; eighty-two, or 13.78 per cent., had double infections; twenty-one, or 3.53 per cent., had triple infections, and three, or 0.5 per cent., had quadruple infections.

Two hundred and nine, or 35.1 per cent., of these individuals were infected with Trichuris trichiura; eighty-six, or 14.62 per cent., were infected with Ascaris lumbricoides; forty-one, or 6.89 per cent., with Oxyuris vermicularis; forty, or 6.72 per cent., with Strongyloides stercoralis; eighteen, or 3 per cent., with Necator americanus; fifty-five, or 9.25 per cent., with Hymenolepis nana, and one, or 0.17 per cent., with Hymenolepis diminuta.

Of the 317 instances of infections, 211 , or 66.56 per cent., were single; eighty-two, or 25.87 per cent., were double; twenty-one, or 6.62 per cent., were triple, and three, or 0.95 per cent., were quadruple.

As to the type of infection in the 317 instances: Trichuris trichiura was offender in 209, or 65.9 per cent.; Ascaris lumbricoides in eightysix, or 27.13 per cent.; Oxyuris vermicularis in forty-one, or 12.93 per cent.; Strongyloides stercoralis in forty, or 12.62 per'cent.; Necator americanus in eighteen, or 5.68 per cent.; Hymenolepis nana in fiftyfive, or 17.35 per cent., and Hymenolepis diminuta in one, or 0.32 per cent.

\section{THE INSTITUTIONS}

The orphan asylum designated in the tables as No. 1 is an institution in which the most complete data could be obtained. Ninety-five individuals were examined, forty-six of whom were males and fortynine females. Seventeen showed infections. Their ages ranged from $11 / 2$ years to 18 years. The previous environment of the inmates was usually known. In seventy-five instances it was unsanitary; and in six sanitary; in fourteen instances the previous environment was unknown. 
The duration of the residence in this institution of those studied ranged from a short period up to twelve years - in the infected cases from six months to ten years.

In the seventeen infected cases in this institution, fifteen were of those whose previous environments were unsanitary, one sanitary and one unknown. The parasitic infection of the seventeen in the group were Trichuris trichiura in ten, or 58.82 per cent., of the instances; Oxyuris vermicularis in six, or 35.29 per cent.; Hymenolepis nana in two, or 11.76 per cent., and Ascaris lumbricoides in one, or 5.88 per cent., of the instances. The double infections were one each of Trichuris trichiura and Ascaris lumbricoides, and Trichuris trichiura and Hymenolepis nana.

There were no animals in the institution. Raw washed fruit and vegetables were eaten. A dietitian is in charge of the institution. There were among the inmates no crawlers, finger suckers or dirt eaters. The stools had been examined once in the past six years. A systematic medical examination is made about twice annually.

In the orphan asylum designated in the tables as No. 2, 125 individuals were examined, 101 , or 80.08 per cent., of whom were infected. There were forty-three males and eighty-two females. Of those infected, forty-three were males and fifty-eight females. It is interesting to note that all the boys showed infections. The ages of the inmates ranged from two to seventeen years. The duration of residence in the institution was unknown. The infections in the 101 cases were as follows: Trichuris trichiura, seventy-three, or 72.29 per cent.; Ascaris lumbricoides, twenty-six, or 25.34 per cent.; Oxyuris vermicularis, nine or 8.91 per cent.; Stronglyloides stercoralis, twenty-one, or 20.89 per cent.; Necator americanus, eight, or 7.92 per cent., and Hymenolepsis nana, fourteen, or 13.86 per cent. The multiple infections were as follows: Trichuris trichiura with Strongyloides stercoralis, eight times; Trichuris trichiura. with Ascaris lumbricoides, six times; Trichuris trichiura with Hymenolepis nana, five times; Trichuris trichiura with Ascaris lumbricoides and Strongyloides stercoralis, four times; Trichuris trichiura with Necator americanus, three times; Trichuris trichiura with Necator americanus, three times; Trichuris trichiura with Oryuris vermicularis, three times, and one time each of the following: Ascaris lumbricoides with Hymenolepis nana; Oxyuris vermicularis with Strongyloides stercoralis; Oxyuris vermicularis with Hymenolepis nana; Strongyloides stercoralis with Necator americanus; Strongyloides stercoralis with Hymenolepis nana; Trichuris trichiura, Ascaris lumbricoides with Necator americanus; Trichuris trichiura, Necator americanus with Hymenolepis nana; Oxyuris vermicularis, Strongyloides stercoralis with Hymenolepis nana; Tri- 
churis trichiura, Ascaris lumbricoides, Oxyuris vermicularis with Strongyloides stercoralis; Trichuris trichiura, Ascaris lumbricoides, Necator americanus with Hymenolepis nana.

The youngest individual in this study found to be infected was in this institution. The child was 2 years of age, and had a quadruple infection of Trichuris trichiura, Ascaris lumbricoides, Oxyuris vermicularis and Strongyloides stercoralis.

The children played with dogs. There was no systematic medical inspection and the stools had never been examined before. Raw washed fruits and vegetables were eaten by the inmates of this institution. Several were dirt eaters, though they were not specified. The previous environments were unknown.

The orphan asylum designated in the tables as No. 3 presented seventy-five individuals for examination, of whom forty-two were males and thirty-three were females, their ages ranging from 4 to 17 years. Of the infected cases, twenty-eight were males and twenty females. The previous environments were not known. The parasitic infections in the forty-eight instances in this group were as follows: Trichuris trichiura in thirty-one, or 64.58 per cent., of the cases; Ascaris lumbricoides in ten, or 20.83 per cent.; Oxyuris vermicularis in eight, or 16.67 per cent.; Strongyloides stercoralis in three, or 6.25 per cent., and Hymenolepis nana in five, or 10.42 per cent.

The multiple infections showed: Trichuris trichiura with Oxyuris vermicularis in five instances; Trichuris trichiura with Ascaris lumbricoides in two instances; Trichuris trichiura with Hymenolepis nana, and Ascaris lumbricoides with Strongyloides stercoralis in one instance each.

There were no dogs or animals in this institution. Raw, washed fruits and vegetables were eaten here. There were no crawling children, dirt eaters or finger suckers. The stools were never examined.

The orphan asylum designated in the tables as No. 4 contributed sixty-seven stools for examination from thirty-nine males and twentyeight females. Their ages ranged from 3 to 14 years. Examination showed twenty-four infections, twelve males and twelve females. The infections were as follows: Trichuris trichiura in fifteen, or 62.5 per cent.; Ascaris lumbricoides in five, or 20.83 per cent.; Hymenolepis nana in five, or 20.83 per cent., and Necator americanus in one, or 4.16 per cent. Double infection occurred twice with the same parasites, namely, Trichuris trichiura with Hymenolepis nana. The habits and surroundings of the inmates of this institution could not be ascertained, except that raw, washed vegetables were eaten here, and the stools had been examined once for hookworm a number of years ago.

The infant's asylum in this study is designated in the tables as 
No. 5. There were 110 stools examined from children ranging in age from 3 weeks to 5 years, of whom seventy-three were males and thirty-seven were females. Of those infected, fifteen were males and six were females. No infections occurred in this institution before the second year. The youngest child was 28 months old, and was infected with Ascaris lumbricoides. This child subsequently died of tuberculosis. There were thirteen single infections and eight multiple infections. Trichuris trichiura infections were found in nine, or 42.85 per cent.; Ascaris lumbricoides in twelve, or 57.14 per cent.; Oxyuris vermicularis in three, or 14.28 per cent.; Hymenolepis nana in four, or 19.04 per cent., and Hymenolepis diminuta, Strongyloides stercoralis and Necator americanus in one, or 4.76 per cent, instances each. The multiple infections were: Trichuris trichiura with Strongyloides stercoralis one time; Trichuris trichiura with Ascaris lumbricoides two times, and the following combination one time each: Ascaris lumbricoides with Hymenolepis nana; Trichuris trichiura with Hymenolepis nana; Trichuris trichiura with Ascaris lumbricoides and Hymenolepis diminuta; and Trichuris trichiura with Ascaris lumbricoides and Oxyuris vermicularis. It is of interest that the rat tape worm, Hymenolepis diminuta, was found in this institution, and in an individual 3 years old. One of the youngest infections in this series occurred in this institution, namely, the child 28 months old infected with Ascaris lumbricoides.

In this institution medical inspection is frequent. The laboratory of the board of health examines stools when a child is suspected, and also makes differential blood examinations in certain conditions when called to do so. There are no dogs or cats in the institution. The children receive both washed and raw vegetables, and fruits and bananas unwashed and raw. Many of these inmates are born in the institution and those entering later come from unsanitary environment. Crawlers, finger suckers and dirt eaters are common here.

The institution designated in the tables as No. 6 is a white waif's home. The stools of fifty-one inmates were examined. All were males whose ages were not obtainable. The percentage of infections in this institution was the greatest in this study, showing forty-six infections in fifty-one individuals, or 90.2 per cent. of the inmates infected. The infections found were: Trichuris trichiura in twenty-nine, or 62.83 per cent. of the infections; Ascaris lumbricoides in fifteen, or 32.61 per cent. ; Oxyuris vermicularis in ten, or 21.74 per cent.; Strongyloides stercoralis in four, or 8.69 per cent.; Necator americanus in four, or 8.69 per cent., and Hymenolepis nana in fourteen, or 13.43 per cent., of the instances. The multiple infections were as follows: Trichuris trichiura with Ascaris lumbricoides in six, or 
13.1 per cent.; Trichuirs trichiura with Ascaris lumbricoides and Hymenolepis nana in six, or 13.1 per cent.; Trichuris trichiura with Hymenolepis nana in three, or 6.52 per cent.; Trichuris trichiura with Ascaris lumbricoides and Necator americanus in two, or 4.36 per cent., and Strongyloides stercoralis with Necator americanus, Strongyloides stercoralis with Hymenolepis nana, and Trichuris trichiura with Ascaris lumbricoides, Strongyloides stercoralis and Hymenolepis nana in one instance each. Mutiple infections occurred in twenty, or 43.48 per cent., of the instances.

The previous environment of the inmates of this institution are rarely sanitary. The population is transient. There is no medical inspection, and while the sanitary conditions are very good, particularly in the pantry and kitchen, the origin, duration of residence and lack of medical inspection may easily be accountable for the heavy infection. There are no dogs or cats in the institution. The vegetables and fruit eaten here are washed.

In the institution designated in the tables as No. 7 , the conditions are identical with those in No. 6. In No. 7 the inmates are colored waifs. The stools of seventy-two individuals were examined showing an infection second in severity only to the white waif's home, as the stools of sixty of the seventy-two inmates were infected, or an 83 per cent. infection. The parasites causing the infection were: Trichuris trichiura in forty-two, or 70 per cent.; Ascaris lumbricoides in seventeen, or 28.33 per cent.; Hymenolepis nana in eleven, or 18.33 per cent.; Oxyuris vermicularis in five, or 8.33 per cent.; Strongyloides stercoralis in eleven, or 18.33 per cent, and Necator americanus in four, or 6.66 per cent. The multiple infections were as follows: Trichuris trichiura with Strongyloides stercoralis in six, or 10 per cent.; Trichuris trichiura with Ascaris lumbricoides in six, or 10 per cent. ; Trichuris trichiura with Hymenolepis nana in four, or 6.66 per cent.; Trichuris trichiura with Ascaris lumbricoides and Strongyloides stercoralis in two, or 3.33 per cent.; Trichuris trichiura with Oxyuris vermicularis in two, or 3.33 per cent, and one, or 1.66 per cent., instances of the following combination: Oxyuris vermicularis with Strongyloides stercoralis; Oxyuris vermicularis with Hymenolepis nana; Ascaris lumbricoides with Strongyloides stercoralis and Hymenolepis nana; Ascaris lumbricoides with Necator americanus and Hymenolepis nana; Ascaris lumbricoides with Necator americanus, and Necatar americanus with Hymenolepis nana. Multiple infections occurred in twenty-six, or 43.33 per cent., of the infections in this institution, the greatest multiple infections occurring in this study.

Age.-The ages of those whose stools were examined ranged from 3 weeks to 18 years, as follows: Under 1 year, fifty-five; 1 year 
and under 2 years, seventeen ; 2 years, three; 3 years, sixteen; 4 years, twenty; 5 years, twenty-one; 6 years, thirteen; 7 years, twenty-four; 8 years, thirty-five; 9 years, thirty; 10 years, thirty-nine; 11 years, forty-eight ; 12 years, forty-five ; 13 years, forty-two; 14 years, twentysix; 15 years, twenty-three; 16 years, ten ; 17 years, three; 18 years, two. In 123 instances the ages were not given.

There were no infections under 2 years. Two years, two, or 0.33 per cent.; 3 years, nine, or 1.51 per cent.; 4 years, ten, or 1.68 per cent. ; 5 years, eight, or 1.34 per cent.; 6 years, ten, or 1.68 per cent. ; 7 years, twelve, or 2.01 per cent. ; 8 years, twenty-four, 4.03 per cent.; 9 years, seventeen, or 2.85 per cent.; 10 years, seventeen, or 2.85 per cent.; 11 years, twenty-seven, or 4.53 per cent.; 12 years, twenty-six, or 4.36 per cent.; 13 years, twenty-one, or 3.52 per cent.; 14 years, fifteen, or 2.52 per cent.; 15 years, eight, or 1.34 per cent.; 16 years, three, or 0.41 per cent. ; 17 years, one, or 0.16 per cent.; 18 years, one, or 0.16 per cent.

Sex.-Of the 595 stools examined, 365 were from males and 230 from females. The 317 infections included 213, or 67.19 per cent. males and 104, or 32.81 per cent., females; 58.38 per cent. of the males and 45.22 per cent. of the females investigated were infected.

The number of males whose stools were examined at the various ages were: Under 1 year, thirty-five; over 1 year and under 2 years, nine ; 2 years, one ; 3 years, ten ; 4 years, ten; 5 years, fifteen ; 6 years, nine; 7 years, fourteen ; 8 years, fourteen ; 9 years, fourteen; 10 years, twenty-two; 11 years, twenty-three; 12 years, twenty; 13 years, eighteen; 14 years, fourteen; 15 years, eight; 16 years, six; 17 years, none; 18 years, none. Of 123 males the ages were not given.

The males infected at the given ages were: 2 years, one, or 0.47 per cent.; 3 years, six, or 2.85 per cent.; 4 years, six, or 2.85 per cent.; 5 years, six, or 2.85 per cent.; 6 years, six, or 2.85 per cent.; 7 years, eight, or 3.8 per cent.; 8 years, nine, or 4.28 per cent.; 9 years, eight, or 3.80 per cent.; 10 years, ten, or 4.74 per cent.; 11 years, fourteen, or 6.7 per cent.; 12 years, fourteen, or 6.7 per cent.; 13 years, five, or 2.37 per cent.; 14 years, seven, or 3.35 per cent.; 15 years, four, or 1.9 per cent. ; 16 years, three, or 1.42 per cent. Of 106 infected males the ages were not given.

The number of females whose stools were examined at the various ages were: Under 1 year, twenty; over 1 year and under 2 years, eight; 2 years, two; 3 years, six; 4 years, ten; 5 years, six; 6 years, four; 7 years, ten; 8 years, twenty-one; 9 years, sixteen; 10 years, seventeen; 11 years, twenty-five; 12 years, twenty-five; 13 years, twenty-four; 14 years, twelve; 15 years, fifteen; 16 years, four; 17 years, three; 18 years, two. 
The females infected at the various ages were: 2 years, one, or 0.31 per cent.; three years, three, or 0.95 per cent.; 4 years, four, or 1.26 per cent.; 5 years, two, or 0.63 per cent. ; 6 years, four, or 1.26 per cent. ; 7 years, four, or 1.26 per cent. ; 8 years, fifteen, or 4.74 per cent.; 9 years, nine, or 2.84 per cent.; 10 years, seven, or 2.21 per cent.;

TABle 1.-The Percentages of the Males and Females Examined at the Various AGes

\begin{tabular}{|c|c|c|c|c|c|c|}
\hline \multirow{2}{*}{$\begin{array}{l}\text { Age, } \\
\text { Years }\end{array}$} & \multicolumn{3}{|c|}{ Males } & \multicolumn{3}{|c|}{ Females } \\
\hline & Examined & $\begin{array}{l}\text { Number } \\
\text { Infected }\end{array}$ & $\begin{array}{l}\text { Per Cent. } \\
\text { Infected }\end{array}$ & $\begin{array}{c}\text { Number } \\
\text { Examined }\end{array}$ & $\begin{array}{l}\text { Number } \\
\text { Infected }\end{array}$ & $\begin{array}{l}\text { Per Cent. } \\
\text { Infected }\end{array}$ \\
\hline $\begin{array}{r}\text { Under } 1 \\
1 \\
2 \\
3 \\
4 \\
5 \\
6 \\
7 \\
8 \\
9 \\
10 \\
11 \\
12 \\
13 \\
14 \\
15 \\
16 \\
17 \\
18\end{array}$ & $\begin{array}{r}35 \\
9 \\
1 \\
10 \\
10 \\
15 \\
9 \\
14 \\
14 \\
14 \\
22 \\
23 \\
20 \\
18 \\
14 \\
8 \\
6 \\
0 \\
0\end{array}$ & $\begin{array}{r}0 \\
0 \\
1 \\
6 \\
6 \\
6 \\
6 \\
6 \\
8 \\
9 \\
8 \\
10 \\
14 \\
14 \\
5 \\
7 \\
4 \\
3 \\
0 \\
0\end{array}$ & $\begin{array}{c}0 \\
0 \\
100 \\
60 \\
60 \\
40 \\
66.6 \\
57 \\
64 \\
57 \\
45.4 \\
61 \\
70 \\
27.8 \\
50 \\
50 \\
50 \\
0 \\
0\end{array}$ & $\begin{array}{r}20 \\
8 \\
2 \\
6 \\
10 \\
6 \\
4 \\
10 \\
21 \\
16 \\
17 \\
25 \\
25 \\
24 \\
12 \\
15 \\
4 \\
3 \\
1\end{array}$ & $\begin{array}{r}0 \\
0 \\
1 \\
3 \\
4 \\
2 \\
4 \\
4 \\
15 \\
9 \\
7 \\
13 \\
12 \\
16 \\
8 \\
4 \\
4 \\
2 \\
1\end{array}$ & $\begin{array}{c}0 \\
0 \\
50 \\
50 \\
40 \\
33.3 \\
100 \\
40 \\
71.5 \\
56.2 \\
41.2 \\
52 \\
48 \\
66.7 \\
66.7 \\
26.6 \\
100 \\
66.7 \\
100\end{array}$ \\
\hline
\end{tabular}

In 123 instances the ages of males examined were not given.

In 106 instances the ages of maies infected were not given.

TABLE 2.-Symptoms Manifested in Infected and Noninfected Cases

\begin{tabular}{|c|c|c|c|c|c|c|}
\hline Symptom & $\begin{array}{c}\text { Number } \\
\text { of } \\
\text { Cases }\end{array}$ & $\begin{array}{c}\text { Per Cent. } \\
\text { of All } \\
\text { Oases }\end{array}$ & $\begin{array}{c}\text { Number } \\
\text { of } \\
\text { Nega- } \\
\text { tive } \\
\text { Cases }\end{array}$ & $\begin{array}{c}\text { Per Cent. } \\
\text { of } \\
\text { Nega- } \\
\text { tive } \\
\text { Cases }\end{array}$ & $\begin{array}{l}\text { Number } \\
\text { of } \\
\text { Infected } \\
\text { Cases }\end{array}$ & $\begin{array}{c}\text { Per Cent. } \\
\text { of } \\
\text { Infected } \\
\text { Cases }\end{array}$ \\
\hline 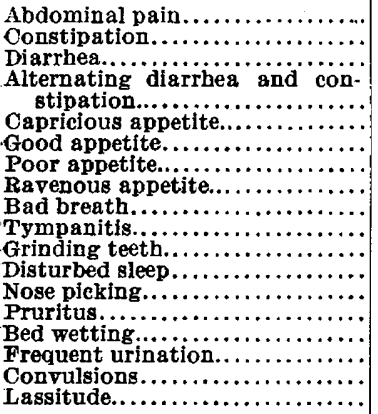 & $\begin{array}{r}19 \\
36 \\
2 \\
2 \\
2 \\
2 \\
14 \\
7 \\
52 \\
43 \\
0 \\
21 \\
14 \\
20 \\
1 \\
7 \\
4 \\
1 \\
49\end{array}$ & $\begin{array}{c}14.3 \\
27.1 \\
1.5 \\
\\
1.5 \\
1.5 \\
10.52 \\
5.25 \\
39.2 \\
33.1 \\
0.0 \\
15.8 \\
10.27 \\
15.05 \\
0.75 \\
5.25 \\
3.0 \\
0.75 \\
36.95\end{array}$ & $\begin{array}{r}16 \\
33 \\
2 \\
\\
1 . \\
2 \\
5 \\
6 \\
42 \\
35 \\
0 \\
14 \\
10 \\
14 \\
1 \\
3 \\
3 \\
1 \\
38\end{array}$ & $\begin{array}{c}16.8 \\
34.8 \\
2.12 \\
\\
1.05 \\
2.12 \\
5.26 \\
6.32 \\
44.2 \\
36.9 \\
0.0 \\
14.7 \\
10.5 \\
14.7 \\
1.5 \\
3.18 \\
3.18 \\
1.05 \\
40.0\end{array}$ & $\begin{array}{r}9 \\
1 \\
10 \\
8 \\
0 \\
7 \\
4 \\
6 \\
0 \\
4 \\
1 \\
11\end{array}$ & $\begin{array}{c}2.37 \\
2.63 \\
26.0 \\
21.4 \\
0.0 \\
18.35 \\
10.52 \\
15.8 \\
0.0 \\
10.52 \\
2.63 \\
28.9\end{array}$ \\
\hline
\end{tabular}

11 years, thirteen, or 4.1 per cent. ; 12 years, twelve, or 3.76 per cent.; 13 years, sixteen, or 5.05 per cent.; 14 years, eight, or 2.52 per cent.; 15 years, four, or 1.26 per cent.; 16 years, none; 17 years, one, or 0.31 per cent.; 18 years, one, or 0.31 per cent. 
Unfortunately, more information could not be secured with regard to the symptoms. In only 133 instances was it possible to secure the symptoms. This included ninety-five negative cases and thirty-eight infected cases.

The comparative frequency of the symptoms attributable to infection with intestinal parasites in the noninfected cases with those infected in this series, even though it is small, should emphasize the necessity of finding either the ova or the parasite itself in making a diagnosis of worms before subjecting an individual, and more especially the infant and small child, to the ordeal of unnecessary medication, as the positive diagnosis is a very simple matter. Especial attention is drawn to the comparative frequency in the noninfected cases with the infected cases where nose picking, grinding of the teeth, disturbed sleep, ravenous appetite and lassitude existed.

THE PARASITES

The parasites found in this series were as follows: Trichuris trichiura; Ascaris lumbricoides; Oxyuris z'ermicularis; Strongyloides stercoralis; Necator americanus; Hymenolepis nana and Hymenolepis diminuta. They appeared singly and in various combinations as shown in Table. 4.

Trichuris trichiura.-This parasite infected 209 individuals. It was a single offender in 120 , or 57.42 per cent., cases; double in sixtyeight, or 32.54 per cent.; triple in eighteen, or 8.61 per cent., and quadruple in three, or 1.43 per cent. Its age incidence was as follows : 2 years, one, or 0.72 per cent.; 3 years, four, or 2.9 per cent.; 4 years, six, or 4.35 per cent.; 5 years, one, or 0.72 per cent. ; 6 years, eight, or 5.8 per cent.; 7 years, six, or 4.35 per cent.; 8 years, eighteen, or 13.04 per cent.; 9 years, fifteen, or 10.87 per cent.; 10 years, sixteen, or 11.59 per cent. ; 11 years, nineteen, or 13.77 per cent.; 12 years, sixteen, or 11.59 per cent.; 13 years, thirteen, or 9.42 per cent.; 14 years, seven or 5.07 per cent.; 16 years, four, or 2.9 per cent.; 16 years, two, or 1.45 per cent.; 17 years, one, or 0.72 per cent.; 18 years, one, or 0.72 per cent., and in seventy-one instances the ages were not given.

Its period of maximum infection was therefore from 8 to 13 years, inclusive, when over 70 per cent. of its infections occurred.

Males and females were infected at the various ages as follows: 2 years, no males and one female; 3 years, three males and one female; 4 years, five males and one female; 5 years, one male and no female; 6 years, four males and four females; 7 years, five males and one female; 8 years, six males and twelve females; 9 years, seven males and eight females; 10 years, nine males and seven females; 11 years, 
eleven males and eight females; 12 years, six males and 10 females; 13 years, four males and nine females; 14 years, three males and four females; 15 years, two males and two females; 16 years, one male and one female; 17 years, no males and one female; 18 years, no males and one female.

Ascaris lumbricoides.-This parasite infected eighty-six individuals. It was a single offender in thirty-six, or 41.86 per cent., of its infections; double in twenty-eight, or 32.56 per cent. ; triple in nineteen, or 22.09 per cent., and quadruple in three, or 3.49 per cent. Its age incidence was as follows: 2 years, two, or 3.7 per cent.; 3 years, four, or 7.4 per cent. ; 4 years, three, or 5.6 per cent.; 5 years, five, or 9.2 per cent.; 6 years, none; 7 years, five, or 9.2 per cent.; 8 years, seven, or 13 per cent. ; 9 years, four, or 7.4 per cent.; 10 years, six, or 11.1 per cent.; 11 years, five, or 9.2 per cent.; 12 years, five, or 9.2 per cent.; 13 years, five, or 9.2 per cent.; 14 years, three, or 5.6 per cent., and in thirty-two instances the ages were not given.

Its period of maximum infection was therefore from 5 to 13 years when over 77 per cent. of its infections occurred.

Males and females were infected at the various ages as follows: 2 years, one male and one female; 3 years, two males and two females; 4 years, two males and one female ; 5 years, four males and one female; 7 years, five males and no females; 8 years, three males and four females; 9 years, no males and four females; 10 years, four males and two females; 11 years, three males and 2 females; 12 years, three males and two females; 13 years, two males and three females; 14 years, three males.

Oxyuris vermicularis.-This parasite infected forty-one individuals. It was a single offender in twenty-three, or 56.10 per cent, of the cases; double in fifteen, or 36.58 per cent.; triple in two, or 4.88 per cent., and quadruple in one, or 2.44 per cent. Its age incidence was as follows : 2 years, one, or 3.85 per cent.; 3 years, none ; 4 years, three, or 11.54 per cent.; 5 years, one, or 3.85 per cent.; 6 years, three, or 11.54 per cent.; 7 years, two, or 7.69 per cent.; 8 years, four, or 15.38 per cent.; 9 years, one, or 3.85 per cent.; 10 years, none; 11 years, one, or 3.85 per cent.; 12 years, two, or 7.69 per cent.; 13 years, one, or 3.85 per cent. ; 14 years, three, or 11.54 per cent.; 15 years, two, or 7.69 per cent. ; 16 years, two, or 7.69 per cent., and in fifteen instances the ages were not given.

There was no period of maximum infection, as the parasite was found rather evenly distributed.

Males and females were infected at the various ages as follows: 2 years, no males and one female; 4 years, two males and one female; 5 years, one male and no female; 6 years, two males and one female; 
7 years no males and two females ; 8 years, one male, and three females; 9 years, one male and no females; 11 years, no males and one female; 12 years, two males and no females; 13 years, no males and one female; 14 years, two males and one female ; 15 years, one male and one female; 16 years, two males and no females.

Strongyloides stercoralis.-This parasite infected forty individuals. It was a single offender in eight, or 20 per cent, of its infections; double in twenty-two, or 55 per cent. ; triple in eight, or 20 per cent., and quadruple in two, or 5 per cent. Its age incidence was a follows: 2 years, one, or 4 per cent.; 3 years, none ; 4 years, one, or 4 per cent.; 5 years, none; 6 years, one, or 4 per cent.; 7 years, three, or 12 per cent.; 8 years, one, or 4 per cent.; 9 years, three, or 12 per cent.; 10 years, four, or 16 per cent.; 11 years, two, or 8 per cent.; 12 years, three, or 12 per cent.; 13 years, three, or 12 per cent.; 14 years, one. or 4 per cent.; 15 years, two, or 8 per cent., and in fifteen instances the ages were not given.

Its period of maximum infection was therefore from 7 to 13 years, inclusive, when 76 per cent. of the infections occurred.

Males and females were infected at the various ages as follows: 2 years, no males and one female; 4 years, no males and one female; 6 years, one male and no females; 7 years, one male and two females; 8 years, one male and no females; 9 years, one male and two females; 10 years, two males, and two females; 11 years, two males and no females; 12 years, three males and no females; 13 years, no males and three females; 14 years, no males and one female; 15 years, no males and two females.

Necator americanus.-This parasite infected eighteen individuals. It was a single offender in 5, or 27.78 per cent., of its infections; double in seven, or 38.89 per cent.; triple in five, or 27.78 per cent., and quadruple in one, or 5.55 per cent. Its age incidence was as follows: 2 years, none; 3 years, one, or 10 per cent.; 7 years, one, or 10 per cent. ; 9 years, one, or 10 per cent. ; 11 years, one, or 10 per cent. ; 12 years, one, or 10 per cent., 13 years, three, or 30 per cent.; 15 years, two, or 20 per cent., and in eight instances the ages were not given.

No period could be considered as of maximum infection with this parasite.

Males and females were infected at the various ages as follows: 3 years, no males and one female; 7 years, one male and no females; 9 years, one male and no females; 11 years, no males and one female; 12 years, no males and one female; 13 years, one male and two females; 15 years, no males and two females.

Hymenolepis nana.-This parasite infected fifty-five individuals. 

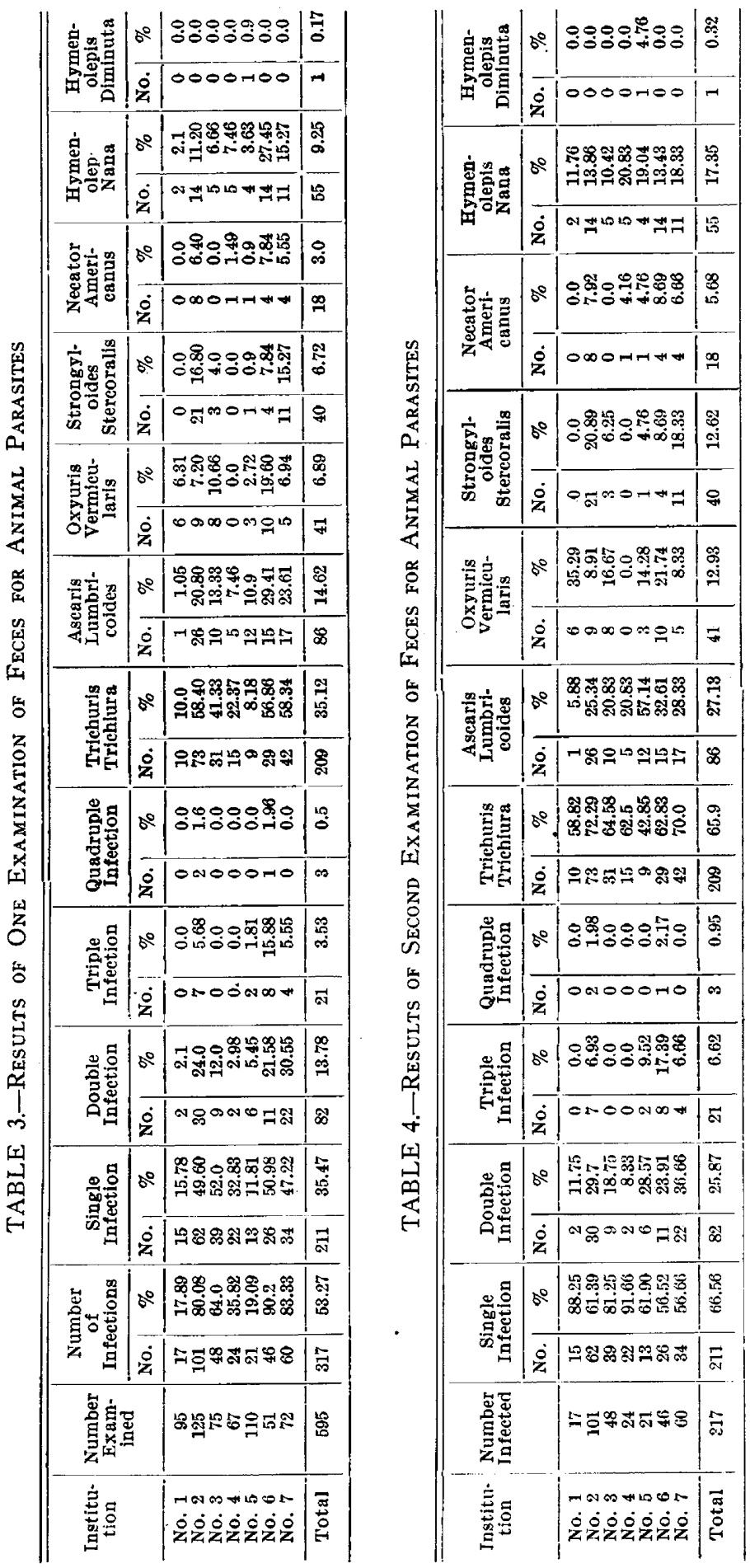
It was a single offender in nineteen, or 34.55 per cent., of its infections; double in twenty-four, or 43.64 per cent. ; triple in ten, or 18.18 per cent., and quadruple in two, or 3.63 per cent. Its age incidence was as follows: 3 years, three, or 10 per cent. ; 4 years, one, or 3.33 per cent.; 5 years, three, or 10 per cent.; 6 years, one, or 3.33 per cent.; 7 years, one, or 3.33 per cent. ; 8 years, two, or 6.67 per cent. ; 9 years, one, or 3.33 per cent.; 11 years, five, or 16.67 per cent.; 12 years; five, or 16.67 per cent.; 13 years, two, or 6.67 per cent.; 14 years, five, or 16.67 per cent., and 16 years, one, or 3.33 per, cent. In twenty-five instances the ages were not given.

In the infection of this parasite there also seemed no period of maximum infection, though 70 per cent. of the infections occurred above the age of 8 years.

Males and females were infected at the various ages as follows: 3 years, three males and no females; 4 years, one female; 5 years, two males and one female; 6 years, one male and no females; 7 years, one male and no females; 8 years, one male and one female; 9 years, no males and one female; 11 years, three males and two females; 12 years, four males and one female; 13 years, no males and two females; 14 years, one male and four females; 16 years, one male and no females.

Hymenolepis diminuta.-This parasite was found in one instance in which there was a triple infection with Trichuris trichiura and Ascaris lumbricoides. The individual infected was a female, 3 years of age.

\section{BLOODS}

The bloods of 307 individuals included in this study were examined. Differential counts were made from the bloods of 124 of the negative cases and 183 of the positive cases. Table 5 gives the numbers and averages of bloods for the different ages for both positive and negative cases, and the average of all the bloods of the negative cases as well as the average of all the bloods of the positive cases. A comparison of the average differential count for all ages shows an increase in the eosinophils of the infected cases of 3.5 per cent. over the average of the noninfected cases, the increase apparently being at the expense of the neutrophils.

In the study of the eosinophils for the averages at the different ages, the variations in negative cases were from 0 to 4.8 per cent. In only three instances, namely, for the ages of 4,8 and 11 years, respectively, were the averages above 4 per cent., and in each of these instances the average was heightened by one or two cases with marked eosinophilia. On the other hand, the averages for the different ages in the positive cases, with the exception of the eighteenth year, where only one case was examined, and where the eosinophils were 2 per 
TABLE 5.-Number of Infected and Noninfected Males and Females of Various Ages

\begin{tabular}{|c|c|c|c|c|c|c|c|c|c|c|c|c|}
\hline \multirow[b]{3}{*}{ Age } & \multicolumn{10}{|c|}{ Institution } & \multirow{2}{*}{\multicolumn{2}{|c|}{ Total }} \\
\hline & \multicolumn{2}{|c|}{1} & \multicolumn{2}{|c|}{2} & \multicolumn{2}{|c|}{3} & \multicolumn{2}{|c|}{4} & \multicolumn{2}{|c|}{5} & & \\
\hline & 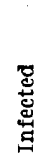 & 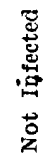 & 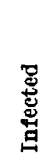 & 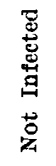 & 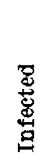 & 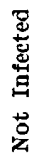 & 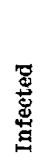 & 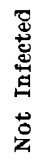 & 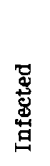 & 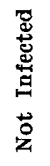 & 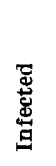 & 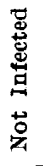 \\
\hline $\begin{array}{l}\text { Under } 1 \text { year } \\
\text { Male...... }\end{array}$ & & & & & & & & & & & & \\
\hline $\begin{array}{l}\text { Male............ } \\
\text { Femar }\end{array}$ & $\ddot{.}$ & $\ddot{.}$ & $\because$. & $\ddot{.}$ & $\ddot{.}$ & $\ddot{\ddot{\prime}}$ & $\ddot{.}$ & $\ddot{.}$ & $\ddot{.}$ & $\begin{array}{l}35 \\
20\end{array}$ & 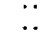 & $\begin{array}{l}35 \\
20\end{array}$ \\
\hline $\begin{array}{c}1 \text { year } \\
\text { Male..... } \\
\text { Female... }\end{array}$ & $\ddot{.}$ & $\ddot{i}$ & $\because$. &.. & $\ddot{.}$ & $\because$ & $\because$. & $\because$. & $\ddot{.}$ & 9 & $\because$. & $\begin{array}{l}9 \\
8\end{array}$ \\
\hline 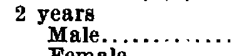 &. & $\cdot \cdot$ & &.. &.. & .. &.. & .. & 1 & & 1 & \\
\hline $\begin{array}{c}\text { Female. } \\
3 \text { years }\end{array}$ & .. & .. & 1 &.. & $\cdot \cdot$ & .. & $\ddot{q}$ & .. & $\ddot{*}$ & 1 & 1 & 1 \\
\hline $\begin{array}{l}\text { Male... } \\
\text { Female. }\end{array}$ & $\because$. & $\ddot{i}$ & $\because$ & $\ddot{i}$ & $\ddot{.}$ & $\because$ & $\begin{array}{l}1 \\
. .\end{array}$ & $\because$. & $\begin{array}{l}5 \\
3\end{array}$ & $\begin{array}{l}4 \\
1\end{array}$ & $\begin{array}{l}6 \\
3\end{array}$ & ${ }_{3}^{4}$ \\
\hline $\begin{array}{l}4 \text { years } \\
\text { Male. }\end{array}$ &. & & 1 & & & 2 & .. & & 5 & 2 & 6 & 4 \\
\hline$\underset{5 \text { years }}{\text { Female. }}$ & $\cdot \cdot$ & 1 & 1 & 1 & 1 & 1 & $\cdot \cdot$ & 1 & 2 & 2 & 4 & 6 \\
\hline Mamale. & $\ddot{i}$ & 1 & $\because$. & $\ddot{2}$ & .2 & $\because$ & $\ddot{.}$ & $\begin{array}{l}1 \\
1\end{array}$ & $\begin{array}{l}4 \\
1\end{array}$ & 7 & ${ }_{2}^{6}$ & $\begin{array}{l}9 \\
4\end{array}$ \\
\hline 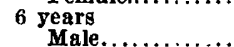 & 1 & $\ddot{2}$ & 3 & & 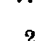 & & & 1 & & & & \\
\hline Female... &.. & $\begin{array}{c}2 \\
. .\end{array}$ & 1 & $\ddot{*}$ & $\frac{2}{3}$ & $\ddot{*}$ & $\because$. & $\begin{array}{l}1 \\
. .\end{array}$ & $\because$. & $\ddot{.}$ & $\begin{array}{l}0 \\
4\end{array}$ &. \\
\hline $\begin{array}{l}7 \text { years } \\
\text { Male.... } \\
\text { Femaie }\end{array}$ & $\cdot$. & 3 & 5 & $\cdots$ & 1 & $\ddot{i}$ & 2 & 3 & .. & .. & 8 & 6 \\
\hline 8 years & & & 2 & 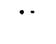 & 1 & 1 & 1 & 4 & .. & .. & 4 & 6 \\
\hline $\begin{array}{l}\text { Male. } \\
\text { Femai }\end{array}$ & $\ddot{i}$ & $\frac{1}{3}$ & $\begin{array}{l}3 \\
9\end{array}$ & $\ddot{i}$ & $\begin{array}{l}5 \\
4\end{array}$ & $\begin{array}{l}1 \\
2\end{array}$ & $\begin{array}{l}1 \\
1\end{array}$ & $\begin{array}{l}3 \\
0\end{array}$ & $\because$. & $\begin{array}{l}. . \\
.\end{array}$ & $\begin{array}{r}9 \\
15\end{array}$ & $\begin{array}{l}5 \\
6\end{array}$ \\
\hline 9 years & & 1 & & & & & & & & & & \\
\hline Famaie... & $\ddot{.}$ & $\begin{array}{l}1 \\
4\end{array}$ & 6 & $\ddot{i}$ & $\ddot{i}$ & 1 & $\begin{array}{l}1 \\
2\end{array}$ & 1 & $\because$. & $\ddot{.}$ & $\stackrel{\circ}{9}$ & 7 \\
\hline $\begin{array}{c}\text { years } \\
\text { Male..... }\end{array}$ & 1 & 5 & ${ }_{6}^{4}$ & $\dddot{q}$ & 4 & 2 & $\frac{1}{1}$ & 5 &.. & $\because \cdot$ & $\begin{array}{c}10 \\
7\end{array}$ & ${ }_{10}^{12}$ \\
\hline 11 years & 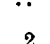 & 4 & 8 & & 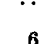 & 2 & 3 & 4 & .. & & 14 & \\
\hline $\begin{array}{l}\text { Femaile... } \\
\text { years }\end{array}$ & 2 & ${ }_{3}^{4}$ & 8 & $\ddot{3}$ & $\begin{array}{l}0 \\
3\end{array}$ & $\frac{1}{2}$ & 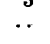 & 4 & $\because$. & $\because$. & 13 & 12 \\
\hline $\begin{array}{l}2 \text { year } \\
\text { Mal } \\
\text { Fem }\end{array}$ & 2 & 3 & 6 & $\ddot{a}$ & 4 & $\stackrel{?}{?}$ & 2 & $\frac{1}{2}$ &.. & $\ddot{*}$ & 14 & 6 \\
\hline $\begin{array}{l}\text { Fem } \\
13 \text { year }\end{array}$ & & & & 4 & & & & 2 & & & & \\
\hline $\begin{array}{l}\text { Male...... } \\
\text { Female... }\end{array}$ & “i & $\begin{array}{l}5 \\
5\end{array}$ & $\begin{array}{l}3 \\
9\end{array}$ & 3 & $\begin{array}{l}1 \\
3\end{array}$ & $\begin{array}{l}3 \\
. \cdot\end{array}$ & $\begin{array}{l}1 \\
3\end{array}$ & 5 & $\ddot{.}$ & $\because$. & $\begin{array}{r}5 \\
16\end{array}$ & $\begin{array}{l}13 \\
.8\end{array}$ \\
\hline $14 \begin{array}{c}\text { years } \\
\text { Male }\end{array}$ & 2 & 5 & 3 &. & 2 & 2 & & & .. &.. & 7 & 7 \\
\hline 15 year & $\cdot \cdot$ & 3 & 7 &.. & .. & .. & 1 & 1 & .. & .. & 8 & 4 \\
\hline $\begin{array}{l}\text { Male...... } \\
\text { Female.. }\end{array}$ & 1 & $\begin{array}{l}4 \\
7\end{array}$ & $\begin{array}{l}3 \\
2\end{array}$ & 3 & $\begin{array}{l}1 \\
1\end{array}$ & 1 & $\because$. & 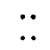 & $\because \ddot{0}$ & $\because$. & $\begin{array}{l}4 \\
4\end{array}$ & $\begin{array}{r}4 \\
11\end{array}$ \\
\hline 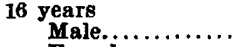 & 1 & 3 & 2 & & & &. & 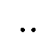 & .. & $\cdot$ & 3 & 3 \\
\hline $\begin{array}{l}\text { Female.... } \\
\text { 17 years }\end{array}$ & $\cdot \cdot$ & 2 & & 1 & 1 & 1 &.. & . & .. & .. & .. & 4 \\
\hline Male $\ldots \ldots \ldots \ldots$ & $\because$. & $\because$. & $\ddot{.}$ & $\ddot{2}$ & $\ddot{i}$ & $\because$. & $\ddot{.}$ & $\because$ & $\because:$ & 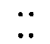 & $\ddot{i}$ & $\ddot{2}$ \\
\hline 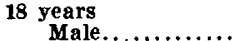 & & & & & & & & & & & & \\
\hline Female.................. & i & $\ddot{i}$ & $\ddot{\ddot{*}}$ & $\because$. & 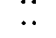 & $\ddot{\ddot{\prime}}$ & $\therefore$ & $\because$. & $\ddot{*}$ & $\ddot{.}$ & $\ddot{i}$ & i \\
\hline Totals... & 17 & 78 & 101 & 24 & 48 & 27 & 24 & 43 & 21 & 89 & 211 & 261 \\
\hline
\end{tabular}


cent., ranged from 4.7 to 9.2 per cent., clearly showing the value of the eosinophilia as an aid in the diagnosis of intestinal parasitic infections.

Further interest is evidenced in the study of the eosinophils of the individual cases. Of the infected cases in three instances there was a 28 per cent. eosinophilia; in one instance there was a 23 per cent. eosinophilia; in one a 22 per cent., in two an 18 per cent., in one a 17 per cent., in one a 16 per cent., in one a 15 per cent., in eight a 14 per cent., in three a 13 per cent., in seven a 12 per cent., in five an 11 per cent., in seven a 10 per cent., in eleven a 9 per cent., in eight an 8 per cent., in twelve a 7 per cent., in fifteen a 6 per cent., in nine a 5 per cent. and in fourteen a 4 per cent. eosinophilia; or in 59.5 per cent. the percentage of eosinophils was four or more; in 51.9 per cent. it was five or more; in 47 per cent., six or more; in 38.7 per cent., seven or more; in 32.2 per cent., eight or more; in 27.8 per cent., nine or more; in 21.8 per cent., 10 or more; in 18 per cent., 11 or more; in 15.3 per cent., 12 or more; in 11.4 per cent., 13 or more; in 9.8 per cent., 14 or more; in 5.4 per cent., 15 or more; in 4.9 per cent., 16 or more; in 4.3 per cent., 17 or more; in 3.8 per cent., 18 or more; in 2.7 per cent., 22 or more; in 2.1 per cent., 23 or more, and in 1.6 per cent. of the infected cases there was a 28 per cent. eosinophil count.

In the noninfected cases in one instance there was an 18 per cent. eosinophilia; in one a 16 per cent. eosinophilia; in two a 13 per cent.; in one a 12 per cent.; in one a 10 per cent.; in four an 8 per cent.; in four a 7 per cent.; in four a 6 per cent.; in five a 5 per cent., and in seventeen a 4 per cent. eosinophilic count; or, in 32 per cent. of the cases the eosinophils numbered 4 per cent. or more; in 18.5 per cent., 5 or more; in 14.5 per cent., 6 or more; in 11.2 per cent., 7 or more; in 8 per cent., 8 or more; in 4.8 per cent., 10 or more; in 4 per cent., 12 or more ; in 3.2 per cent., 13 or more ; in 1.6 per cent., 16 or more, and in 0.8 per cent. of the noninfected cases there was an 18 per cent. eosinophil count. These results are of especial interest, because, while an eosinophilia should suggest an intestinal parasitic infection, it is not pathognomonic of it.

It is of interest to note that of the positive cases all the eosinophilias from 15 per cent. and above were in the same institution (No. 2).

In studying the eosinophils in their relattion to the infections of the various parasites singly and in combination, the following. was revealed: The maximum eosinophilia in the single infection by the Trichuris trichiura was 15 per cent., which occurred in one instance. While, on the other hand, there were two infections by this parasite in which there were no eosinophils shown in the count. The eosinophil count was 4 per cent. or less, as follows: In fourteen instances 
the percentage was 1 per cent. ; in nine it was 2 per cent.; in six it was 3 per cent., and in seven it was 4 per cent.

The maximum eosinophilia in connection with the single infection with the Ascaris lumbricoides was 16 per cent.; the minimum 0.0 per cent. The eosinophil count was 4 per cent. or less, as follows: One patient had a 1 per cent., four patients had a 4 per cent., two patients had a 3 per cent., and three patients had a 4 per cent.

TABLE 6.-Parasites and Number of Times Each Was Found Alone or Associated With OTHers

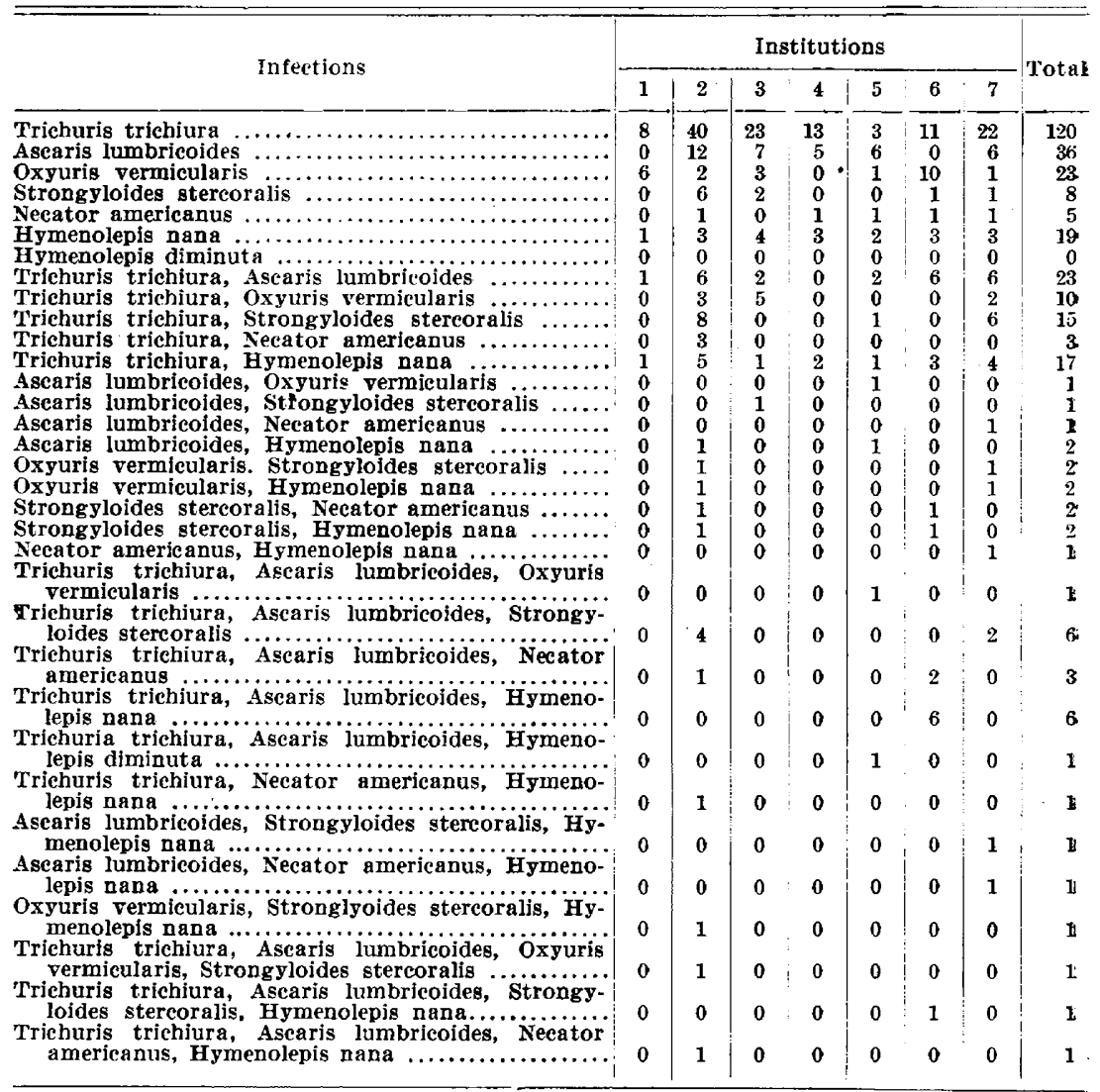

The Oxyuris vermicularis showed a maximum of 11 per cent. eosinophils in single infections and a minimum of 0.0 per cent. The eosinophil count was 4 per cent. or less, as follows: In four instances there was one case with 1 per cent.; three cases with 2 per cent.; two cases with 3 per cent., and two cases with 4 per cent.

The Strongyloides stercoralis in single infection showed a 14 per cent. maximum eosinophil count and a 0.0 per cent. minimum count. 
The eosinophil count was 4 per cent. or less, as follows: There was one case with 1 per cent., and one case with 2 per cent.

The Necator americanus occurred only in two instances in single infection, once with a 12 per cent. and the other time with a 13 per cent. eosinophil count. It is of interest to note that the lowest eosinophil counts with this parasite in combination under 4 per cent. were 1 per cent. with a mixed infection with Trichuris trichiuria and Hymenolepis nana in one instance, and in a double infection with Strongyloides stercoralis in which the eosinophil count was 3 per cent.

Hymenolepis nana showed in a single infection a maximum of 18 per cent. eosinophils, and in three instances the percentage was zero. The eosinophil count was 4 per cent. or less, as follows: There were three instances of 1 per cent., and one of 2 per cent.

TABLE 7.-Results of Examination of Blood in Infected and Noninfected CASES

\begin{tabular}{|c|c|c|c|c|c|c|c|c|c|c|c|c|}
\hline \multirow[b]{2}{*}{ Age } & \multicolumn{6}{|c|}{ Not Infected } & \multicolumn{6}{|c|}{ Infected } \\
\hline & 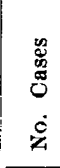 & 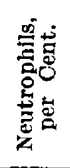 & 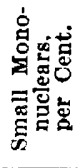 & 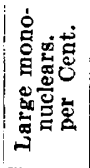 & 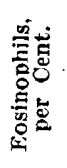 & 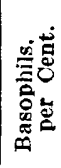 & 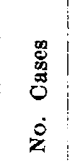 & 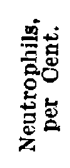 & 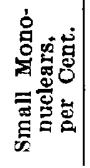 & 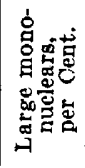 & 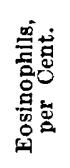 & 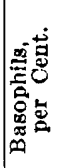 \\
\hline 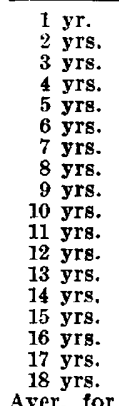 & $\begin{array}{r}1 \\
0 \\
2 \\
5 \\
3 \\
2 \\
5 \\
8 \\
8 \\
13 \\
13 \\
15 \\
16 \\
10 \\
15 \\
7 \\
0 \\
1 \\
\end{array}$ & $\begin{array}{l}44.0 \\
36.5 \\
55.5 \\
52.7 \\
59.0 \\
62.8 \\
57.1 \\
57.9 \\
57.6 \\
60.6 \\
63.4 \\
61.1 \\
58.4 \\
63.1 \\
60.8 \\
\ldots 6.0 \\
66.0 \\
\end{array}$ & $\begin{array}{l}56.0 \\
\ldots \ldots .5 \\
48.5 \\
38.8 \\
42.3 \\
35.0 \\
32.4 \\
35.6 \\
35.6 \\
37.6 \\
32.6 \\
32.1 \\
36.0 \\
37.3 \\
33.5 \\
35.4 \\
\ldots 3.0 \\
32.0 \\
\end{array}$ & $\begin{array}{l}- \\
0.5 \\
0.1 \\
0.2 \\
2.5 \\
1.8 \\
2.3 \\
3.3 \\
1.8 \\
2.5 \\
2.1 \\
1.4 \\
1.5 \\
1.4 \\
2.4 \\
\ldots .2 \\
0.2 \\
\end{array}$ & $\begin{array}{l}\overline{-} \\
0.5 \\
5.0 \\
3.0 \\
3.5 \\
2.8 \\
4.8 \\
3.1 \\
3.0 \\
4.2 \\
2.3 \\
1.4 \\
2.8 \\
1.9 \\
1.4 \\
\ldots .0 \\
0.0\end{array}$ & $\begin{array}{l}- \\
2 \\
0 \\
0 \\
0 \\
2 \\
2 \\
1 \\
0 \\
1 \\
1 \\
1 \\
0 \\
1 \\
0 \\
0 \\
0\end{array}$ & \begin{tabular}{r|}
0 \\
1 \\
7 \\
10 \\
8 \\
10 \\
9 \\
92 \\
13 \\
15 \\
23 \\
21 \\
16 \\
14 \\
7 \\
3 \\
3 \\
1 \\
\end{tabular} & $\begin{array}{l}\overline{40.0} \\
47.6 \\
50.5 \\
53.4 \\
58.2 \\
57.7 \\
57.3 \\
57.0 \\
63.0 \\
57.8 \\
57.2 \\
54.9 \\
58.3 \\
55.6 \\
57.4 \\
62.0 \\
72.0 \\
\end{array}$ & \begin{tabular}{l|}
- \\
45.0 \\
39.9 \\
39.3 \\
36.4 \\
32.1 \\
31.0 \\
35.4 \\
33.2 \\
30.3 \\
35.3 \\
23.7 \\
36.4 \\
35.8 \\
38.4 \\
32.6 \\
28.0 \\
25.0 \\
\end{tabular} & $\begin{array}{r}- \\
5.0 \\
.6 .0 \\
5.5 \\
4.1 \\
2.1 \\
1.3 \\
9.0 \\
1.2 \\
1.1 \\
2.1 \\
2.2 \\
1.0 \\
1.0 \\
6.0 \\
3.0 \\
2.0 \\
1.0 \\
\end{array}$ & $\begin{array}{l}- \\
9.0 \\
6.3 \\
4.7 \\
5.7 \\
7.0 \\
9.3 \\
6.3 \\
8.4 \\
5.5 \\
4.7 \\
6.5 \\
7.6 \\
4.8 \\
5.3 \\
7.0 \\
8.0 \\
2.0 \\
\end{array}$ & $\begin{array}{l} \\
1 \\
2 \\
0 \\
4 \\
6 \\
2 \\
1 \\
2 \\
1 \\
1 \\
4 \\
1 \\
1 \\
1 \\
0 \\
0 \\
0 \\
\end{array}$ \\
\hline all cases & 124 & 59.92 & 35.39 & 1.9 & 2.71 & 0.08 & 183 & 56.27 & 35.26 & 2.01 & 6.27 & 0.19 \\
\hline
\end{tabular}

In only one case was the Hymenolepis diminuta found, in which instance it was in a triple infection with Trichuris trichiura and Ascaris lumbricoides. The eosinophil count in this case was 13 per cent.

The maximum eosinophil count in the double infection was 28 per cent. in two instances, both being combined infections with the Trichuris trichiura and Strongyloides stercoralis. The minimum eosinophilia in this combination was 1 per cent. in one instance. There were no others below 6 per cent.

The minimum eosinophil count in a double infection was zero in a mixed infection of Trichuris trichiura with Ascaris lumbricoides. 
In two double infections the count was 1 per cent., namely, Trichuris trichiura with Ascaris lumbricoides, and Trichuris trichiura with Oxyuris vermicularis. In four instances there was a 2 per cent.; in two instances a 3 per cent., and in three instances a 4 per cent. eosinophil count.

In the triple infections the maximum eosinophil count was 28 per cent. in a combined infection of Trichuris trichiura, Ascaris lumbricoides and Strongyloides stercoralis. The minimum count was zero with an infection of Trichuris trichiura, Ascaris lumbricoides and Oxyuris vermicularis; and 1 per cent. in a triple infection of Trichuris trichiura, Necator americamus and hymenolepis nana.

The blood was examined in two quadruple infections, the eosinophil counts being 9 and 8 per cent., respectively. In the former the combined infections were of the Trichuris trichiura, Ascaris lumbricoides, Oxyuris vermicularis and Strongyloides stercoralis, and in the latter Trichuris trichiura, Ascaris lumbricoides, Necator americanus and Hymenolepis nana. It is of especial interest that in the former infection the individual was a child, 2 years of age.

\section{CONCLUSIONS}

1. In this study the frequency of the infections by the various parasites were: Trichuris trichiura, Ascaris lumbricoides, Hymenolepis nana, Oxyuris vermicularis, Strongyloides stercoralis, Necator americanus and Hymenolepis diminuta.

2. The hygiene, general care, duration of residence in the institution, previous environment, association with dogs, eating of dirt, absence of systematic medical inspection, seemed to have a direct bearing on the frequency of intestinal parasitic infection.

3. The two institutions where systematic medical inspections were made, even though there were many crawlers in one of these institutions, showed the lowest percentages of infections, namely, 17.89 per cent. and 19.00 per cent., respectively.

4. The two institutions with the heaviest infections were those where the population was transient and where there were no medical inspections, the infections being 90.2 and 83.33 per cent., respectively.

5. The youngest individual infected was in the least sanitary of the institutions investigated, this child was 2 years of age and had a quadruple infection of Trichuris trichiura, Ascaris lumbricoides, Oxyuris vermicularis, and Strongyloides stercoralis.

6. The relation of age to infection seemed negligible except that there were no infections among the infants; in other words, before the period of exposure there were no infections. The maximum number of infections occurred at the age of 11 years. 
7. Males were infected over 13 per cent. more frequently than were females. Again the element of exposure seems to have had some influence. The maximum ages of the infections in boys were 11 and 12 years, and for girls, 13 years. Infections, however, were rather generally distributed over several years.

8. No information of value was obtained in studying the incidence at the different ages, except that the greatest incidence in boys was fourteen infections in twenty boys, or 70 per cent. of infections at the age of 12 years, and for the girls fifteen in twenty-one, or 71.5 per cent. of infections at the age of 8 years.

9. The symptoms usually attributed to "having worms" were as frequent, and some a little more frequent, in those not infected than in those infected.

10. One infection with the rat tape worm (Hymenolepis diminuta) was found in a female child, 3 years of age. The infection occurred in a triple infection of Hymenolepis diminuta and Trichuris trichiura with Ascaris lumbricoides.

11. An eosinophilia is a valuable aid in the diagnosis of infection with intestinal parasites. It is, however, not pathognomonic of, and its absence does not exclude, an infection.

12. The eosinophils were found as high as 28 per cent. in the positive cases, and 18 per cent. in the negative cases. They were 4 per cent. or above in 59.5 per cent. of the positive cases, and 4 per cent. above in 32 per cent. of the negative cases. It was of interest that all the eosinophilias of 15 per cent. and above in the positive cases occurred in the same institution.

13. No parasite in this study seemed to have a definite eosinophilia.

14. It was shown that the infection by any of the intestinal parasites in this study could exist with an absence of eosinophils. This was found in their single infections with the exception of Necator americanus and Hymenolepis diminuta. Necator americamus was found in single infections in only two cases, in which instances the eosinophils were 12 and 13 per cent., respectively. However, in mixed infection of this parasite with Trichuris trichiura and Hymenolepis nana the eosinophils were as low as 1 per cent.

The other exception was the Hymenolepis diminuta which was not found in single infection, but in combination with Trichuris trichiura and Ascaris lumbricoides in which case the eosinophils numbered 13 per cent.

15. Minimum eosinophil counts in double and triple infections were zero, while the maximum was 28 per cent. in each. 
16. The two quadruple infections in which blood examinations were done showed an 8 and 9 per cent. eosinophilia, respectively.

17. The diagnosis of intestinal parasitic infection is an extremely easy matter. The symptoms usually ascribed to worms are as frequent in those not infected as in those infected. Blood examinations showing eosinophilias are valuable diagnostic aids, but the only way to make a positive diagnosis is by either finding the parasite or the ova in the stool of the individual. Vermifuges should, therefore, not be given to the defenseless child unless it is known that an infection exists and its character is ascertained when the specific drug may be given to combat the infection. 